\title{
Additive Manufacturing of Ceramic Materials: a Performance Comparison of Catalysts for Monopropellant Thrusters
}

\author{
Robert-Jan Koopmans ${ }^{1}$ and Sebastian Schuh ${ }^{2}$ and Tobias Bartok ${ }^{3}$ \\ FOTEC Forschungs- und Technologietransfer GmbH, Viktor Kaplan-Straße 2, 2700 Wiener Neustadt, Austria \\ Yann Batonneau ${ }^{4}$ and Corentin Maleix ${ }^{5}$ and Romain Beauchet ${ }^{6}$ \\ CNRS UMR 7285, IC2MP, University of Poitiers, France \\ Martin Schwentenwein ${ }^{7}$ and Manfred Spitzbart ${ }^{8}$ \\ Lithoz GmbH, Mollardgasse 85a/2/64-69, 1060 Wien, Austria \\ and \\ Carsten Scharlemann ${ }^{9}$ \\ Fachhochschule Wiener Neustadt GmbH, Johannes Gutenberg-Straße 3, 2700 Wiener Neustadt, Austria
}

This paper presents the first results of monopropellant decomposition tests obtained from monolithic ceramic catalysts produced by means of additive layer manufacturing techniques and using ceramic precursors. The purpose is to compare the performance of printed monoliths with traditionally manufactured catalysts as well as different washcoat layers, both with respect to decomposition of highly concentrated hydrogen peroxide. Decomposition tests revealed that the manufacturing process does not influence the transient pressure performance but is noticeable in the transient temperature performance. The influence of the thermal mass is seen when comparing two different washcoat layers. Initial results also indicate that too much active phase has an adverse influence on the transient temperature performance.

\section{Nomenclature}

$\begin{array}{ll}A & =\text { surface area } \\ A_{\text {sol }} & =\text { solid surface area of the catalyst cross section } \\ D & =\text { catalyst diameter } \\ c & =\text { heat capacity } \\ h & =\text { heat transfer coefficient } \\ L & =\text { catalyst length } \\ P & =\text { sum of the channel perimeters } \\ P_{\text {intial }} & =\text { initial/ambient pressure } \\ P_{s s} & =\text { steady state pressure }\end{array}$

\footnotetext{
${ }^{1}$ Senior Research Scientist, Department of Aerospace Engineering, koopmans@fotec.at, no AIAA member.

${ }^{2}$ Junior Research Scientist, Department of Aerospace Engineering, no AIAA member.

${ }^{3}$ Junior Research Scientist, Department of Aerospace Engineering, no AIAA member.

${ }^{4}$ Assistant Professor, Chemistry Department, yann.batonneau@univ-poitiers.fr, senior AIAA member.

${ }^{5}$ PhD student, Chemistry Department, corentin.maleix@univ-poitiers.fr, no AIAA member

${ }^{6}$ Assistant Professor, Chemistry Department, romain.beauchet@ univ-poitiers.fr, no AIAA member

${ }^{7}$ Head of Material Development, mschwentenwein@lithoz.at, no AIAA member.

${ }^{8}$ Application Engineer, mspitzbart@ lithoz.at, no AIAA member.

${ }^{9}$ Head of Aerospace Engineering University of Applied Sciences Wiener Neustadt, carsten.scharlemann@fhwn.ac.at, AIAA member
} 


$\begin{array}{ll}t & =\text { time } \\ T & =\text { temperature } \\ T_{0} & =\text { initial temperature } \\ T_{\text {intial }} & =\text { initial/ambient temperature } \\ T_{s s} & =\text { steady state temperature } \\ T_{\infty} & =\text { temperature away from the wall } \\ V & =\text { volume } \\ \rho & =\text { density } \\ \tau_{\mathrm{P}} & =\text { pressure rise time } \\ \tau_{\mathrm{T}} & =\text { temperature rise time } \\ & \\ \text { ADN } & =\text { Ammonium Dinitramide } \\ \text { cpsi } & =\text { channels per square inch } \\ \text { FCV } & =\text { flow control valve } \\ \text { HAN } & =\text { Hydorxylammonium nitrate } \\ \text { HTP } & =\text { High Test Peroxide }\end{array}$

\section{Introduction}

$\mathbf{M}_{\mathrm{T}}$

ONOPROPELLANT propulsion systems mostly rely on the rapid decomposition of a propellant on a catalyst. The net effect of the decomposition process is a significant rise in temperature of the products often accompanied with a phase change from liquid to gas. Typical temperatures encountered in the reaction chamber range from about $945^{\circ} \mathrm{C}$ for 98 wt. \% hydrogen peroxide ${ }^{1}$ to about $1900{ }^{\circ} \mathrm{C}$ for $\mathrm{ADN}^{2}$ and $2200{ }^{\circ} \mathrm{C}$ for $\mathrm{HAN}^{3}$ based propellants, respectively.

Over the past two decades, catalysts for HTP, ADN and HAN propellant blends have received a lot of attention due to an increased interest in possible replacements for hydrazine ${ }^{4-7}$. A particular difficulty with catalysts for ionic liquids is that a certain amount of preheating is required to initiate the decomposition process ${ }^{8,9}$. This has system disadvantages such as necessary heating power (typically $\sim 10 \mathrm{~W}$ for a $10 \mathrm{~N}$ thruster) and the required time for preheating (typically $30 \mathrm{~min}$ ), reducing the agility of the system. Although preheating of catalysts is common for monopropellant hydrazine thrusters, the required level of preheating is generally less compared to catalysts for ionic liquids. Furthermore, hydrazine catalysts can be operated in cold conditions if necessary albeit shortening the catalyst lifetime, whereas decomposition of ionic liquids would not take place on a cold catalyst at the current state of technology.

Current catalysts for ADN- and HAN-based propellants have many similarities with catalysts for hydrazine thrusters. First and foremost, they are mostly of the particulate type. Here the catalyst consists of particles with a predefined range of sizes, often expressed in terms of mesh numbers, and sometimes predefined shape. Most catalysts of the particulate type consist of a ceramic support structure impregnated with an active phase. One of the most well-known catalysts is the S405 catalyst, formerly Shell 405, used in hydrazine thrusters since the 60's ${ }^{10}$. Despite its extensive use, particulate type catalysts have a couple of significant disadvantages: a large pressure drop over the catalyst bed and the tendency of attrition due to abrasion ${ }^{11}$. Catalysts for ADN- and HAN-based propellants suffer from these same disadvantages. This, in combination with the preheating requirements, reduces the number of potential missions for which ionic liquid propulsion systems offer advantages over hydrazine systems.

The H2020-funded RHEFORM project aims at further developing the ADN technology in order to provide an alternative to hydrazine for a much wider field of space missions ${ }^{12}$. One of the goals is to develop catalysts that allow a lower amount of preheating. To develop such a catalyst, several aspects are investigated such as the choice of active phase, washcoat procedure, monolith material and form. The latter refers to the internal and external shape of the catalyst. Traditionally monoliths are manufactured by pressing a ceramic paste through an extrusion die. The catalyst designer of such monoliths has the possibility to set the shape and size of the channels as well as the length of the monolith. However, the resulting monolith always has straight channels. As such the design degrees of freedom is limited to two dimensions only.

Recently, a technique was developed by Lithoz $\mathrm{GmbH}$ to print ceramic structures ${ }^{13}$. Contrary to manufacturing by extrusion, printing makes monoliths with complex 3D internal structures possible. This opens up the possibility to optimise a catalyst such that the conversion rate is maximal for a minimal pressure drop. Besides that, as a monolith consists of one piece, abrasion is not an issue. Within the RHEFORM project the first steps are taken to further develop catalysts based on additive layer manufacturing. 
This paper presents the results of a series of tests with such monoliths performed as part of the RHEFORM project. The tests consisted of decomposition tests to investigate the steady state and transient performance for different types of monoliths. The tests were performed with $87.5 \mathrm{wt}$ \% HTP, but are believed to be a good representation for other propellants relying on decomposition. Section 2 describes the test objective and setup. The test procedure is explained in section 3. The results are presented in section 4 and further discussed in section 5 .

\section{Test objective and setup}

The goal of the test campaign was to determine how printed ceramic monoliths compare to traditionally manufactured ones, and how a different washcoat influences the results when subjected to a flow of highly concentrated hydrogen peroxide. Although the RHEFORM project is dedicated to propulsion systems with ADN fuel blends, the results of the current test campaign are believed to be independent of the chemical properties of the propellant. In other words, HTP is considered to be a good simuli propellant for which the results as presented in this work are equally valid for other monopropellants that rely on decomposition. Besides that there is a large amount of experience with HTP at FOTEC and IC2MP ${ }^{4,14,15}$, which makes it easier to design and interpret the tests.

The baseline for comparison was a monolith made from cordierite with $600 \mathrm{cpsi}$ (channels per square inch) straight channels and a length of $10.1 \mathrm{~mm}$. It was washcoated with a dedicated sol to get an alumina-based porous layer and impregnated with Pt. This catalyst was compared to monoliths made from two different cordierite slurries. The difference between the two is the size of the ceramic particles in the solution. Three monoliths were printed from each slurry. Two of each slurry were subsequently washcoated and impregnated in the same way as the extruded catalyst. The third monolith of each slurry received a different washcoating procedure, but did have the same active phase. These steps are described in more detail in Ref. 16.

The seven catalysts were tested in a setup of which a CAD drawing is shown in Figure 1. A solenoid valve, hereafter referred to as FCV, controls the flow of HTP to the decomposition chamber. HTP is injected with a porous injector element into the decomposition chamber where the catalyst is located. The injector head is fixed to the decomposition chamber by means of a flange and sealed by a copper ring. Downstream of the catalyst and upstream of the throat two K-type thermocouples are located: one in the centre of the chamber and one halfway between the centre and the decomposition chamber wall. An access port provides the access of the thermocouples to the interior of the decomposition chamber. The same port is also used for pressure measurements. In this way the dribble volume is minimised as much as possible. The disadvantage is that any pressure oscillations that may be present in the decomposition chamber will be attenuated and thus not be measured or measured to a limited extent only.

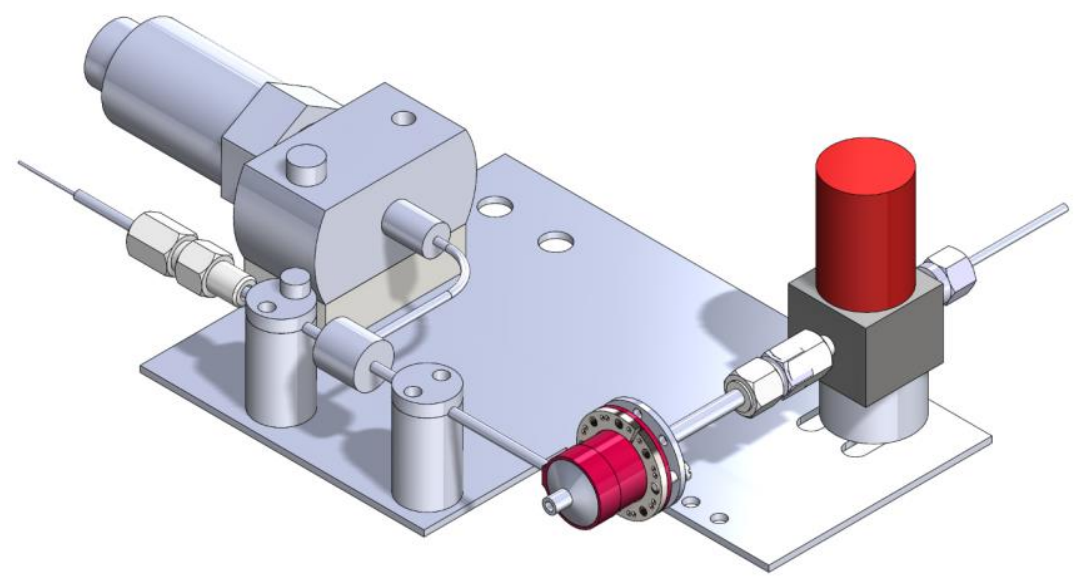

Figure 1. CAD drawing of the test setup

\section{Procedure}

Each catalyst in this comparison was fired four times. A typical test starts with the FCV closed. Temperature and pressure are recorded for $10 \mathrm{~s}$. After $10 \mathrm{~s}$ the FCV is opened and remains open for $200 \mathrm{~s}$. After $200 \mathrm{~s}$ the FCV is closed but the measurements continue for another $60 \mathrm{~s}$. Finally, after the $270 \mathrm{~s}$ the test is finished. Throughout the whole tests all measurements are taken at a frequency of $100 \mathrm{~Hz}$. All tests were carried out at a tank pressure of 16 bar resulting in an HTP mass flow rate of about $0.28 \mathrm{~g} / \mathrm{s}$. The next test does not start before all measured temperatures are within two degrees of the ambient temperature. The whole test procedure is controlled by LabView. 
The test results are used to investigate the steady state and transient performance of the temperature and the pressure. Steady state pressure and temperature are determined by taking the average of the values measured between 120 and $170 \mathrm{~s}$ into the test, i.e. the average over $50 \mathrm{~s}$ or 5000 measurement points. The transient performance is expressed in terms of the rise time and indicated as $\tau_{\mathrm{P}}$ and $\tau_{\mathrm{T}}$ for pressure and temperature, respectively. These performance indicators are explained with the help of Figure 2 and Figure 3.

For $\tau_{\mathrm{P}}$ value the initial pressure level, $\mathrm{P}_{\mathrm{initial}}$, and the steady state pressure, $\mathrm{P}_{\mathrm{ss}}$, need to be measured. As is shown in Figure 2 the pressure rise is characterised by a steep increase to about $95 \%$ of the total pressure increase followed by a gradual increase to its final steady state value.

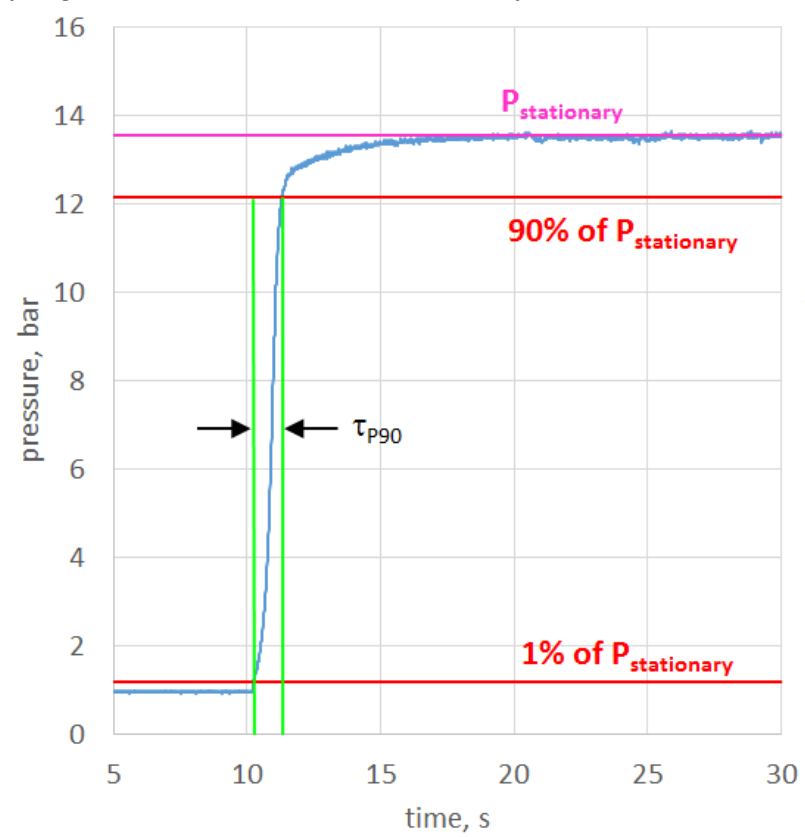

Figure 2. Definition of $\tau_{\mathrm{P}}$

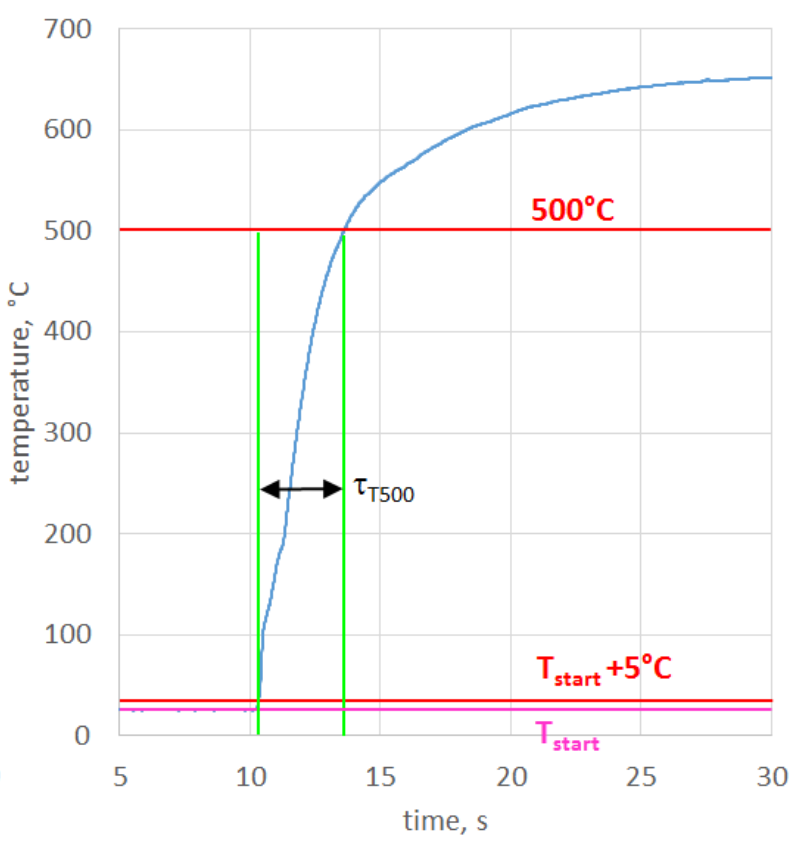

Figure 3. Definition of $\tau_{T}$

The intial steep increase is due to the rapid increase in gas mass as a result of the reactions taking place in the chamber and the corresponding large increase in temperature. The gradual increase to the final steady state value is related to the time it takes for the structure to heat up and reach thermal equilibrium with its environment. The time required for the slow increase to steady state can be reduced by optimising the system design, i.e. reducing thermal mass, whereas the intial steep increase is related to the reactivity of the system (catalyst effectiveness in case of decomposition and effectiveness of droplet breakup, mixing and evaporation in case of auto-ignition, thermal ignition and hypergolic reactions).

The pressure rise time is now defined as the time delay between the initial increase in pressure and the moment the pressure reaches a predefined fraction of the total pressure increase. The fraction is indicated with a number signifying the percentage of total pressure increase. So, $\tau_{\mathrm{P} 90}$ refers to the time elapsed between the initial pressure increase and the moment $90 \%$ of the total pressure increase is reached. For practicality, the initial pressure increase is the moment at which the pressure increase has reached $1 \%$ of the total pressure increase. If the total pressure increase is defined as $\Delta P_{s s}=P_{s s}-P_{\text {initial }}$, then $\tau_{\mathrm{Pa}}$ is defined as

$$
\tau_{P \alpha}=t\left(\frac{\alpha}{100} \Delta P_{s S}\right)-t\left(0.01 \Delta P_{s s}\right)
$$

where $\alpha$ indicates the percentage of total pressure increase. Figure 2 indicates the time delay for a value of $\alpha=$ 90 , or $\tau_{\mathrm{P} 90}$.

For the $\tau_{\mathrm{T}}$ value the initial temperature needs to be measured and a threshold temperature needs to be defined. The initial temperature from which the time measurement starts is defined as the temperature at the start of the test plus $5 \mathrm{~K}$. In this way the start time is unambiguously defined. The threshold value is a temperature of interest for the particular propellant. This can be, for instance, the temperature at which the liquid boils, at which thermal decomposition takes place or at which auto-ignition with a fuel occurs. The threshold temperature is indicated with a number in the subscript. 
The temperature rise time is now defined as the time it takes for the temperature to climb from an initial increase of $5 \mathrm{~K}$ to $\alpha \mathrm{K}$, or

$$
\tau_{T \alpha}=t(T=\alpha)-t\left(T=T_{\text {initial }}+5 \mathrm{~K}\right)
$$

Figure 3 shows the time delay to reach $500{ }^{\circ} \mathrm{C}$, indicated as $\tau_{\mathrm{T} 500}$. Note that for $\tau_{\mathrm{T}}$ values the initial temperature needs to be specified. For a correct comparison the initial temperatures of tests and/or systems that are compared need to be the same or be very similar. Here 'very similar' means that the deviation in comparison to the total temperature increase should be negligible.

\section{Test results}

\section{A. Comparison of slurries}

Table 1 lists the loading characteristics, mass and dimensions of the tested catalysts. The monolith of catalyst GC299 was manufactured by means of extrusion; all others were printed. The designation C822 and C856 refer to the particular slurry that was used.

A large difference in monolith mass is apparent between the traditionally manufactured and the printed monolith, with the latter almost twice as heavy. The outer dimensions of all the monoliths are more or less the same. The explanation for the difference in mass should therefore be sought in the difference in wall thickness and porosity of the material. For all catalysts the relative amount of washcoat is very similar. The relative amount of active phase is similar for RM-C822-03 and RM-C856-06 compared to GC299. RM-C822-05 and RM-C856-04 have a higher amount of active phase.

Table 1. Loading characteristics and dimensions of tested catalysts for slurry comparison

\begin{tabular}{lccccc}
$\begin{array}{l}\text { Catalyst } \\
\text { name }\end{array}$ & $\begin{array}{l}\text { mass } \\
\text { monolith [g] }\end{array}$ & $\begin{array}{l}\text { wt.\% washcoat } \\
\text { layer w.r.t. } \\
\text { monolith }\end{array}$ & $\begin{array}{l}\text { wt.\% active phase } \\
\text { w.r.t. washcoat } \\
\text { layer }\end{array}$ & $\begin{array}{l}\text { catalyst } \\
\text { diameter [mm] }\end{array}$ & $\begin{array}{l}\text { catalyst } \\
\text { length [mm] }\end{array}$ \\
\hline GC299 & 0.7123 & 14.1 & 26.3 & 11.78 & 10.08 \\
RM-C822-03 & 1.3961 & 14.5 & 22.2 & 11.78 & 10.60 \\
RM-C822-05 & 1.4705 & 13.1 & 59.0 & 11.86 & 10.54 \\
RM-C856-04 & 1.2993 & 13.3 & 43.6 & 12.12 & 10.74 \\
RM-C856-06 & 1.3053 & 14.0 & 27.7 & 12.16 & 10.71
\end{tabular}

Figure 4 and Figure 5 show the steady state temperature results for both slurries in comparison with GC299. The average temperatures are indicated by means of symbols. The error bars indicate the spread by means of twice the standard deviation. Also indicated in both figures is the adiabatic decomposition temperature of $87.5 \mathrm{wt}$. \% HTP for an assumed inlet temperature of $20^{\circ} \mathrm{C}$ by means of a black dashed line.

The average temperatures fluctuate between 680 and $705{ }^{\circ} \mathrm{C}$. Note that in most cases the average temperature is higher than the adiabatic decomposition temperature. The HTP is stored in a fridge and gradually warming up to room temperature during tests. In most cases the HTP temperature is below $20{ }^{\circ} \mathrm{C}$ when put in the tank. During operation the temperature of the structure, including the part upstream of the catalyst, increases. This causes the temperature of the HTP prior to injection to increase as well. It is believed that the temperature at which the HTP enters the decomposition chamber is in reality higher than the assumed temperature of about $20^{\circ} \mathrm{C}$. 


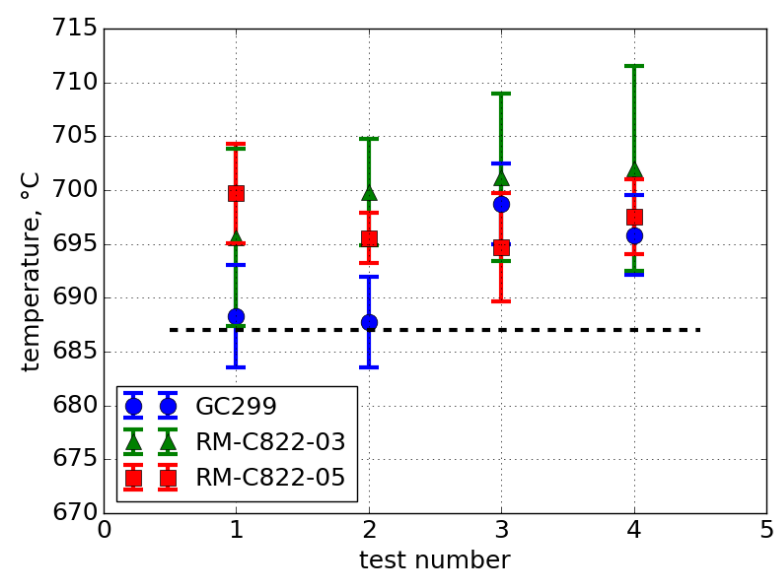

Figure 4. Steady state temperature for slurry C822

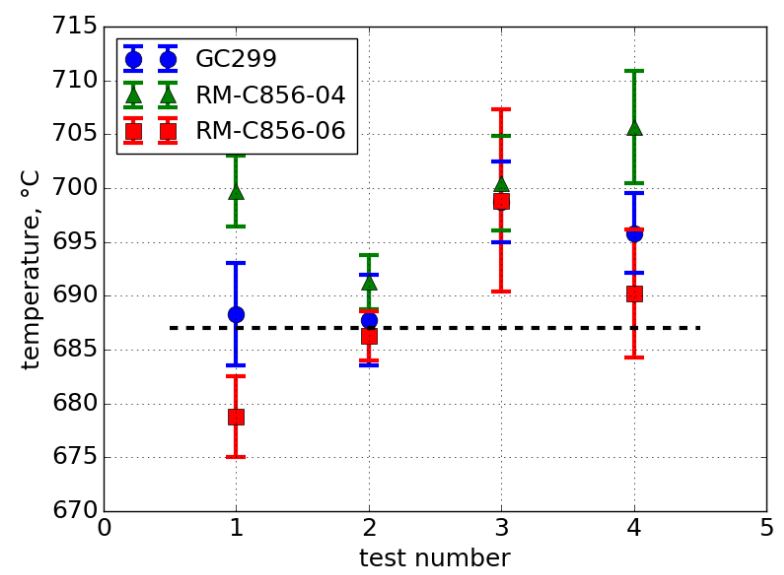

Figure 5. Steady state temperature for slurry C856

The transient performance is shown in Figure 6 through Figure 9. The $\tau_{\mathrm{T}}$-values were determined for different temperatures for monoliths produced from slurry C822 and C856 and are shown in Figure 6 and Figure 7, respectively. The $\tau_{\mathrm{P}}$-values for slurry C 822 and C 856 are shown in Figure 8 and Figure 9, respectively. Note that the vertical axes have different time scales. In neither case a distinction is made in the order in which the results were obtained.

Figure 6 shows that two out of four runs with monoliths from slurry C822 resulted in very large transient times for the temperature. Only in one case, i.e. for slurry C856, the pressure transient time showed a large deviation, see Figure 9. A smaller deviation seems to be present in one of the pressure transient results for slurry C822, see Figure 8. In none of the cases the cause could be determined; no change in operational procedure had occurred. 


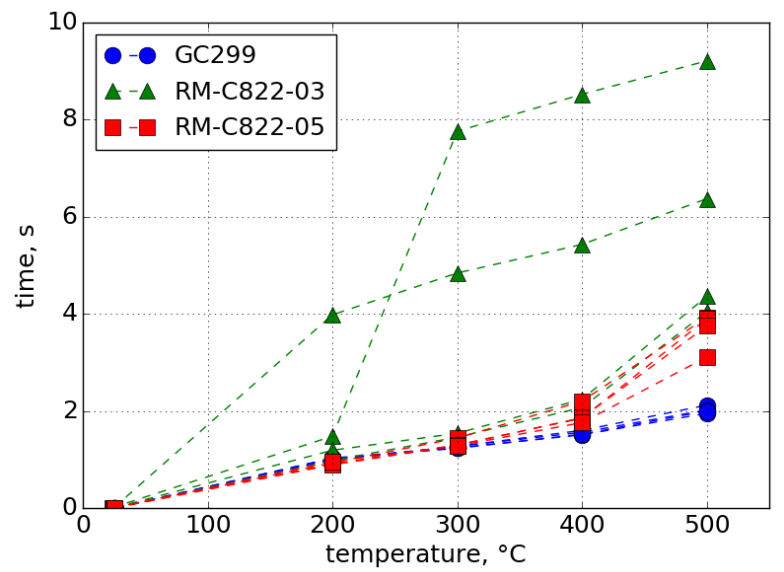

Figure 6. Transient temperature results for slurry $\mathrm{C822}$

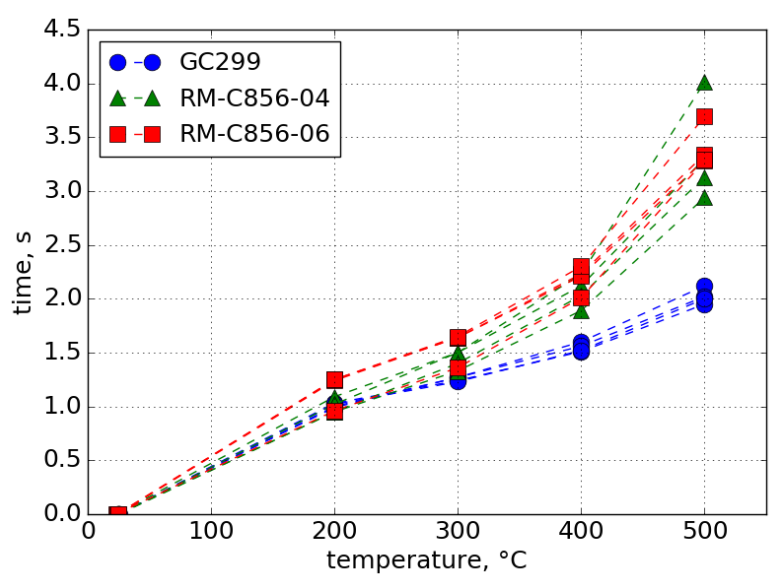

Figure 7. Transient temperature results for slurry $\mathbf{C 8 5 6}$

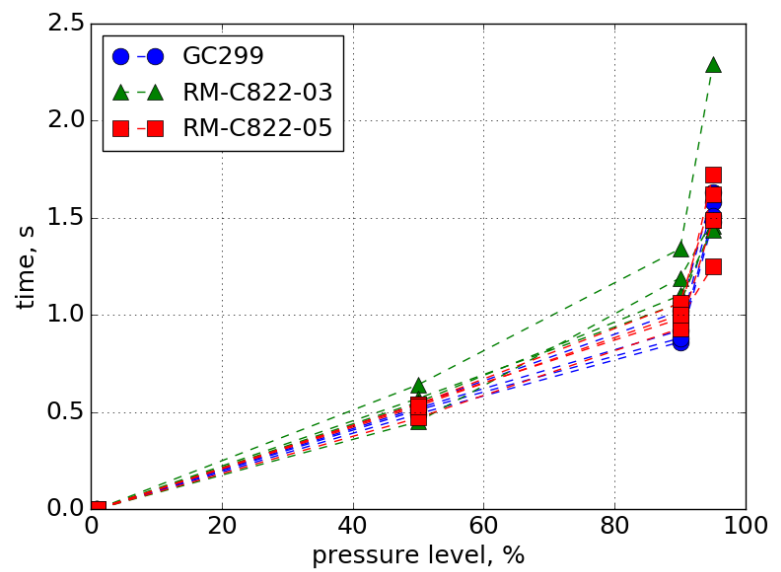

Figure 8. Transient pressure results for slurry C822 


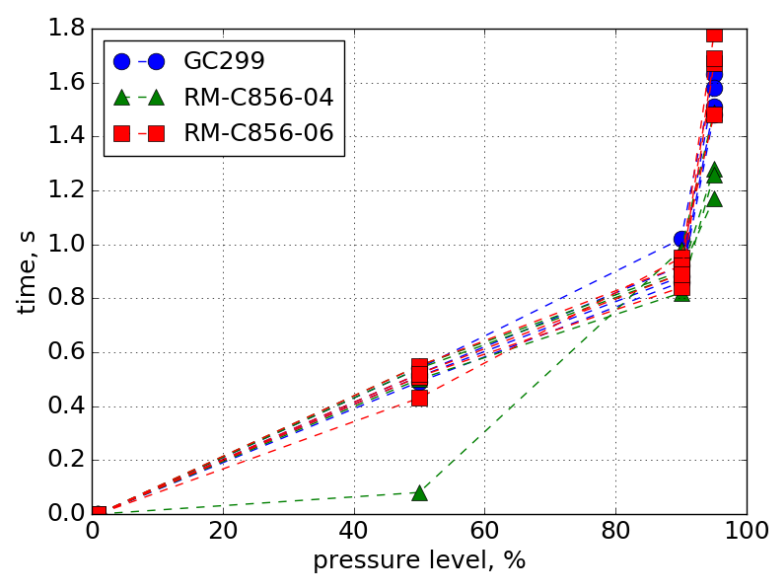

Figure 9. Transient pressure results for slurry $\mathbf{C 8 5 6}$

\section{B. Comparison of washcoat procedures}

A new washcoating procedure was developed specifically for ADN-based propellants. The influence of this washcoating procedure, designated as DUS, as opposed to the established procedure, designated as AU (or B in older publications), was investigated with both slurry C822 and slurry C856. The loading characteristics for the catalysts with this washcoat are shown in Table 2, together with the characteristics of CG299 for reference purposes. As with the catalysts described in the previous section, also these catalysts have a higher mass than the traditionally manufactured ones. The amount of washcoat is slightly different between both printed catalysts. The relative amount of active phase is practically the same between the printed catalysts but different compared to the extruded one. However, in absolute terms GC299 and RM-C822-01 have the same amount of active phase whereas it is $66 \%$ higher for RM-C856-01.

Table 2. Loading characteristics and dimensions of tested catalysts for washcoat comparison

\begin{tabular}{lccccc}
$\begin{array}{l}\text { Catalyst } \\
\text { name }\end{array}$ & $\begin{array}{l}\text { mass } \\
\text { monolith [g] }\end{array}$ & $\begin{array}{l}\text { wt.\% washcoat } \\
\text { layer w.r.t. } \\
\text { monolith }\end{array}$ & $\begin{array}{l}\text { wt.\% active phase } \\
\text { w.r.t. washcoat } \\
\text { layer }\end{array}$ & $\begin{array}{l}\text { catalyst } \\
\text { diameter [mm] }\end{array}$ & $\begin{array}{l}\text { catalyst } \\
\text { length [mm] }\end{array}$ \\
\hline GC299 & 0.7123 & 14.1 & 26.3 & 11.78 & 10.08 \\
RM-C822-01 & 1.4749 & 10.5 & 19.1 & 11.76 & 10.50 \\
RM-C856-01 & 1.3955 & 18.1 & 17.6 & 12.09 & 9.90
\end{tabular}

The results for the steady state performance are shown in Figure 10. In all cases the average temperature is at or above the adiabatic decomposition temperature, as was the case for all but 2 of the tests described in the previous section. Contrary to the steady state results for the different slurries presented in Figure 4 and Figure 5, all average values for the extruded catalysts are lower than for the printed catalysts with the DUS washcoat layer. The average temperature range is the same, however. The absolute differences are small. 


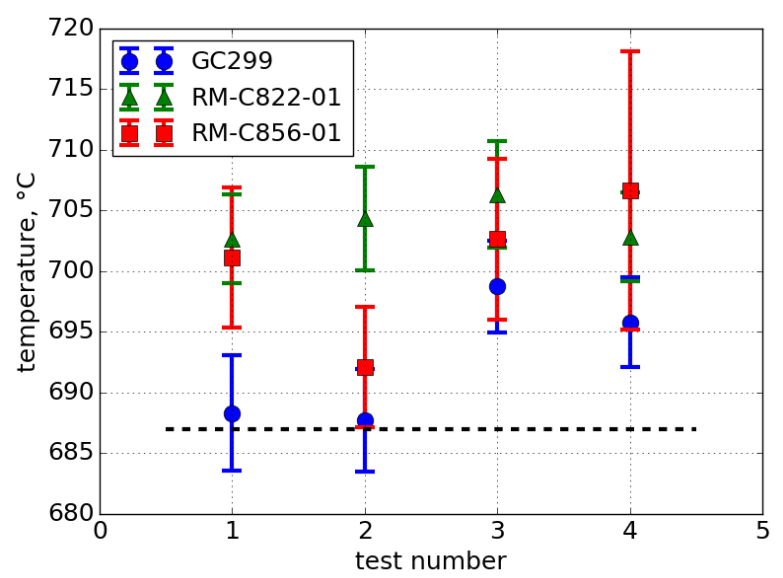

Figure 10. Steady state results for the DUS catalysts

Figure 11 and Figure 12 show the results for the $\tau_{\mathrm{T}^{-}}$and $\tau_{\mathrm{P}}$-values. They are qualitatively the same as the results presented in Figure 6 through Figure 9. However, in absolute terms the $\tau_{\text {T500-values are about a full second lower for }}$ the DUS washcoat compared to the $\mathrm{AU}(\mathrm{B})$ washcoat. This reduction is for both slurries the same. The $\tau_{\mathrm{T} 200}$ and $\tau_{\mathrm{T} 300}$-values seem to be consistently lower for slurry C856 compared to C822. The $\tau_{\mathrm{P}}$-values shown in Figure 12 do not seem to be influenced by the difference in washcoat layer or catalyst mass.

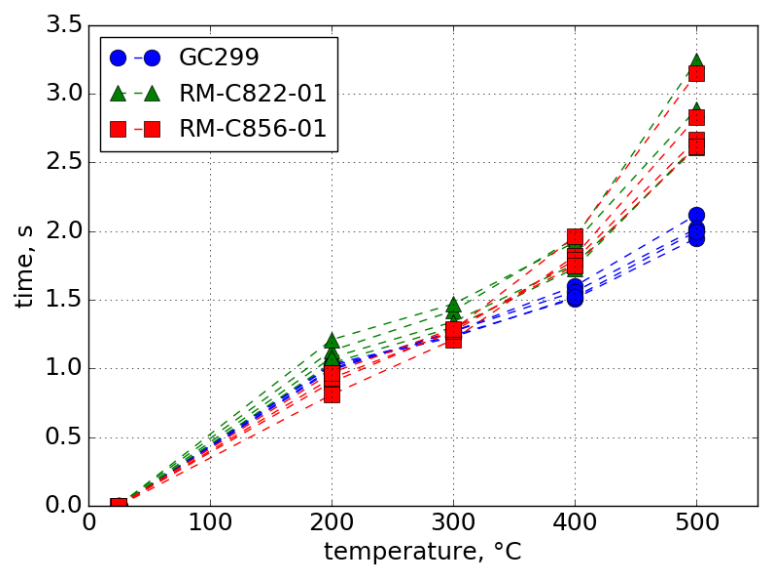

Figure 11. Transient temperature results for DUS catalysts

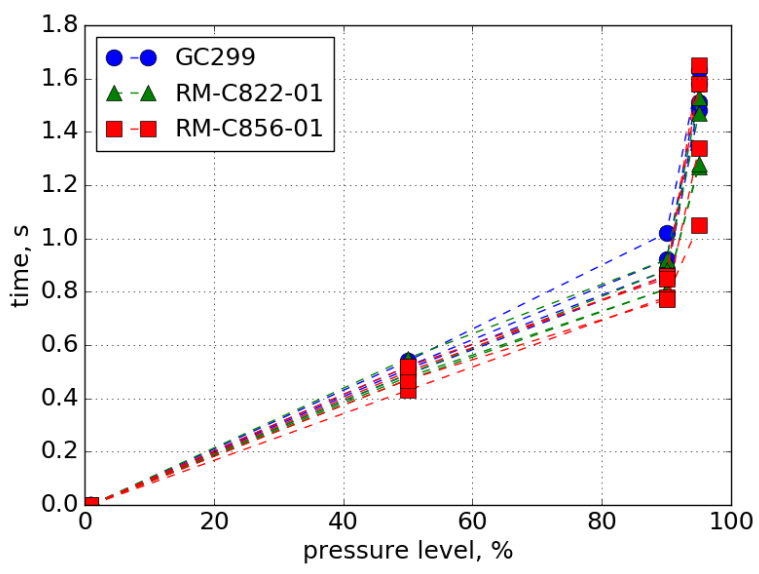

Figure 12. Transient pressure results for DUS catalysts

\section{Discussion}

\section{A. Slurry variation}

As is shown in Figure 4 and Figure 5, between the tests with one and the same catalyst some variations in average temperature as well as in spread are present. These variations seem to be irregular, i.e. not monotonically inor decreasing, and cannot be explained by initial aging effects of the catalyst or by the variation in catalyst mass or amount of active phase. The reason for this variation is currently unknown.

The variation in results between the different catalysts is of the same order as the variation between different tests with a single catalyst. In most cases the temperature range is overlapping. Note that in the steady state plots, the temperature measurement uncertainty is not taken into account. The $2 \sigma$ uncertainty at temperatures of about $700{ }^{\circ} \mathrm{C}$ is approximately $4{ }^{\circ} \mathrm{C}$. Taking this into account as well would result in temperature measurements which are overlapping each other. From this it is concluded that there is no difference in steady state temperature between extruded or printed monoliths or between any of the two slurries.

As far as the transient pressure performance is concerned, there seems to be no difference between either of the catalysts, apart from two runs as was already indicated in the previous section. This means that the reactivity of the 
catalysts is very similar. As can be seen in Table 1, the relative amount of washcoat layer is almost the same for each catalyst. The variation in amount of active phase does not seem to have any influence.

A clear influence on the transient temperature performance is present as is shown in Figure 6 and Figure 7. Catalyst RM-C822-05 seems to perform a little bit better for all temperature levels, despite the slightly higher catalyst mass. The larger mass seems to be offset by the higher amount of active phase present. No distinction in results is noticeable between RM-C856-04 and RM-C856-06. For these catalysts, the mass and amount of washcoat are very similar. Comparing slurry C822 with C856 in Figure 4 and Figure 5, not taking into account the two runs of RM-C822-03 showing outliers, does not reveal any significant difference between the two catalysts.

To quantify the effect of catalyst mass, a simplified thermal transient analysis was carried out. For this purpose the heat transfer from the fluid to the channel walls is modelled as

$$
A h\left(T-T_{\mathrm{sec}}\right)=-\rho V c \frac{d T}{d t}
$$

As the channel walls are relatively thin, between 0.3 and $0.5 \mathrm{~mm}$, it is assumed that the temperature across the channel walls is uniform, i.e. the Biot number is assumed to be small. Now equation (3) can be written in terms of a non-dimensional temperature difference

$$
\frac{d}{d t}\left(\frac{T-T_{W 0}}{T_{0}-T_{W 0}}\right)+\frac{\hbar A}{\rho V C}\left(\frac{T-T_{W 0}}{T_{0}-T_{W 0}}\right)=0
$$

The general solution of this differential equation is given by

$$
\frac{T-T_{\infty}}{T_{0}-T_{\infty}}=a \cdot \exp \left(-\frac{h A t}{\rho V c}\right)
$$

where $a$ is a constant of integration dependent on the initial conditions. For the catalysts under investigation, the initial conditions are assumed to be the same and consequently $a$ is the same as well.

For a first approximation, it is further assumed that the heat transfer coefficient, density and heat capacity are the same for all catalysts. If now a certain non-dimensional temperature level is considered then the time for the catalyst to reach this temperature level is dependent on the factor $A / V$. This ratio was established for catalyst GC299, RMC822-05 and RM-C856-04 and is listed in Table 3. Note that, here the area is the surface area of the channel walls and the volume the volume of the solid. As they are both taken w.r.t. the same catalyst, this ratio can be calculated by dividing the perimeter $P$ by the solid surface area of the cross section $A_{\text {sol. }}$. Given the $A / V$-ratios in Table 3 and equation (5), to achieve the same temperature difference, catalyst RM-C822-05 would take 2.1 times longer and catalyst RM-C856-04 would take 1.7 times longer, i.e. $(A / V)_{G C 299} /(A / V)_{R M}$.

Table 3. Catalyst dimensions of selected catalyst for slurry comparison

\begin{tabular}{lccccccccc} 
catalyst name & $\begin{array}{c}\text { mass } \\
{[\mathbf{m g}]}\end{array}$ & $\boldsymbol{D}[\mathbf{m m}]$ & $\boldsymbol{L}[\mathbf{m m}]$ & $\begin{array}{c}\boldsymbol{A}_{\text {sol }} \\
{\left[\mathbf{m m}^{2}\right]}\end{array}$ & $\boldsymbol{P}[\mathbf{m m}]$ & $\begin{array}{c}\boldsymbol{A} / \boldsymbol{V} \\
{\left[\mathbf{m m}^{-1}\right]}\end{array}$ & $\begin{array}{c}\text { mass } \\
\text { ratio }\end{array}$ & $\begin{array}{c}\boldsymbol{V}_{\text {sol }} \\
\text { ratio }\end{array}$ & $\begin{array}{c}\text { density } \\
{\left[\mathbf{g ~ c m}^{-3}\right]}\end{array}$ \\
\hline GC299 & 846.3 & 11.78 & 10.08 & 49.2 & 387.3 & 7.9 & 1 & 1 & 1.71 \\
RM-C822-05 & 1709.4 & 11.86 & 10.54 & 76.0 & 281.7 & 3.7 & 2.0 & 1.6 & 2.13 \\
RM-C856-04 & 1442.9 & 12.12 & 10.74 & 72.4 & 335.9 & 4.6 & 1.7 & 1.6 & 1.86
\end{tabular}

Figure 13 shows the $\tau_{\mathrm{T}}$-values for catalysts RM-C822-05 and RM-C856-04 as ratio of the average $\tau_{\mathrm{T}-\mathrm{Values}}$ of catalyst GC299. Catalyst RM-C856-04 requires on average less time to reach $200{ }^{\circ} \mathrm{C}$ than catalyst RM-C822-04, even less than GC299, but more time to reach $500{ }^{\circ} \mathrm{C}$ than the other two catalysts. As is clear from this figure, the ratio is not a constant value, as would be expected from the theory described above, but increases with temperature. This suggests that the influence of the thermal mass of the catalyst on the performance becomes important only for higher temperatures. Furthermore, Figure 13 seems to show an exponential relationship between the temperature and the time relative to catalyst GC299. This suggests that the original assumption that the temperature across the solid wall is constant, is not valid between the initial temperature rise and reaching steady state temperature. For the current catalysts in the above described configuration this is between 1 and $2 \mathrm{~s}$ from the opening of the FCV. However, at $500{ }^{\circ} \mathrm{C}$ the relative time w.r.t. catalyst GC299 shown in Figure 13 roughly corresponds to the relative $A / V$-ratio, i.e. $(A / V)_{G C 299} /(A / V)_{R M}$, as was predicted above. In other words, if the transient temperature performance 
should be maximised, an important parameter to maximise during the design of the internal geometry is the $A / V$ ratio.

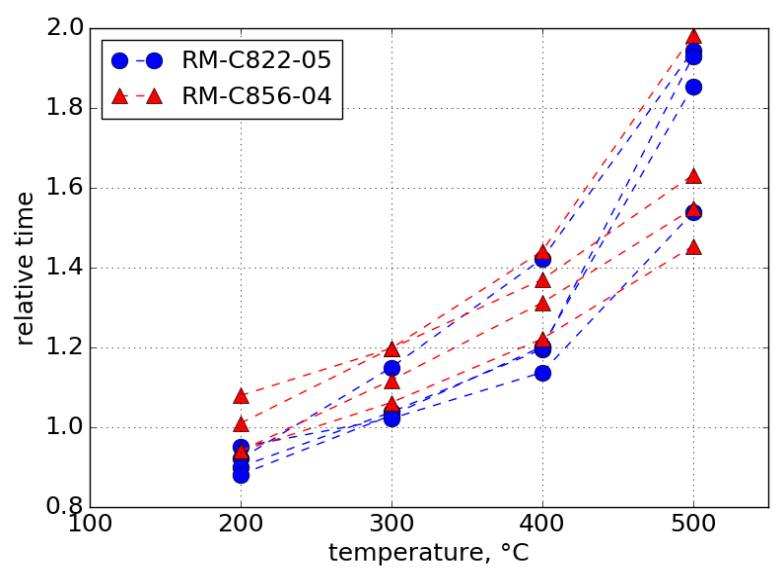

Figure 13. $\tau_{\mathrm{T}}$-values relative to $\mathrm{GC299}$

Columns 8 and 9 in Table 3 show the mass of the catalyst relative to the one of GC299 and the volume of the solid phase relative to the volume of the solid phase of GC299, respectively. The volume of the solid phase was determined by multiplying the cross sectional area of the solid phase, i.e. column 5, with the length of the catalyst. Comparison of columns 8 and 9 shows that the mass ratio is very different from the volume ratio for catalyst RMC822-05 and close but not quite the same for catalyst RM-C856-04. As the material for all three catalysts is the same, from this result it is concluded that the porosity of the printed support structure is different from, i.e. less than, the porosity of the extruded monolith. Furthermore, slurry C822 results in denser structures than slurry C856. The calculated density for each structure is shown in the last column of Table 3.

It would be natural to consider the surface area to density ratio, i.e. $A / \rho$, the parameter to be optimised as this directly relates the mass of the structure to the area over which the heat transfer takes place. Here, $A$ is determined in the same way as described above, i.e. the perimeter $P$ multiplied by the length of the catalyst. The values for the relative surface area to density ratio, i.e. $(A / \rho)_{G C 299} /(A / \rho)_{R M}$ for RM-C822-05 and RM-C856-04 are 1.64 and 1.18, respectively. Although this gives the same relative order as for the relative $A / V$-ratio, the actual values do not correspond to the results shown in Figure 13. For this reason the $A / V$-ratio is preferred to the $A / \rho$-ratio as the parameter to be optimised.

\section{B. Washcoat variation}

The results for both the steady state as well as the transient phase are qualitatively the same as for the slurry variation presented in the previous section. The new washcoat procedure does not influence the steady state temperature. Although the steady state temperature seems to be consistenly lower for the extruded catalyst, see Figure 10, taking into account the measurement uncertainty shows that the measurements are overlapping.

Table 4. Catalyst dimensions of selected catalyst for washcoat comparison

\begin{tabular}{lccccccccc} 
catalyst name & $\begin{array}{c}\text { mass } \\
{[\mathbf{m g}]}\end{array}$ & $\boldsymbol{D}[\mathbf{m m}]$ & $\boldsymbol{L}[\mathbf{m m}]$ & $\begin{array}{c}\boldsymbol{A}_{\text {sol }} \\
{\left[\mathbf{m m}^{2}\right]}\end{array}$ & $\boldsymbol{P}[\mathbf{m m}]$ & $\begin{array}{c}\boldsymbol{A} / \boldsymbol{V} \\
{\left[\mathbf{m m}^{-1}\right]}\end{array}$ & $\begin{array}{c}\text { mass } \\
\text { ratio }\end{array}$ & $\begin{array}{c}\boldsymbol{V}_{\text {sol }} \\
\text { ratio }\end{array}$ & $\begin{array}{c}\mathbf{d e n s i t y} \\
{\left[\mathbf{g ~ c m}^{-3}\right]}\end{array}$ \\
\hline GC299 & 846.3 & 11.78 & 10.08 & 49.2 & 387.3 & 7.9 & 1 & 1 & 1.71 \\
RM-C822-05 & 1709.4 & 11.86 & 10.54 & 76.0 & 281.7 & 3.7 & 2.0 & 1.6 & 2.13 \\
RM-C856-04 & 1442.9 & 12.12 & 10.74 & 72.4 & 335.9 & 4.6 & 1.7 & 1.6 & 1.86 \\
RM-C822-01 & 1474.9 & 11.76 & 10.50 & 84.1 & 292.4 & 3.5 & 1.7 & 1.8 & 1.67 \\
RM-C856-01 & 1395.5 & 12.09 & 9.90 & 78.7 & 319.9 & 4.1 & 1.7 & 1.6 & 1.79
\end{tabular}

Table 4 summarises the geometric characteristics of the tested catalysts in the same way as was done in Table 3. For ease of comparison RM-C822-05 and RM-C856-04 are included as well. The calculated densities in the last column show that the porosity for RM-C856-01 is very similar to the catalyst with the same slurry but another washcoat layer. This is not the case for slurry C822; RM-C822-01 is less dense than RM-C822-05, even less dense than the reference catalyst. A possible explanation for this difference is that RM-C822-05 has a relatively large amount of active phase, see Table 1. For the DUS washcoat variant of both slurries the relative amount of active phase is less compared to all other catalysts. As the active phase consists of the heavy element Pt, heavier than 
cordierite, this could explain the differences in density. A more detailed analysis of the contribution of each component of the catalyst, i.e. support structure, washcoat layer, and active phase, is currently carried out but at the time of writing not yet finished.

A comparison in transient time for $\tau_{\mathrm{P} 90}$ of the DUS and the AU(B) washcoated catalysts relative to the $\tau_{\mathrm{P} 90^{-}}$ values is shown in Figure 14. Regardless of the slurry, the DUS washcoat layer seems to perform better, i.e. result in lower transient times, than the AU(B) washcoat layer. This is especially noticeable for slurry C822. More tests with catalysts made from slurry C856 are required to draw the same firm conclusion. In all cases the catalysts with a DUS washcoat layer have an equal or faster transition time than the $\mathrm{AU}(\mathrm{B})$ washcoated catalysts.

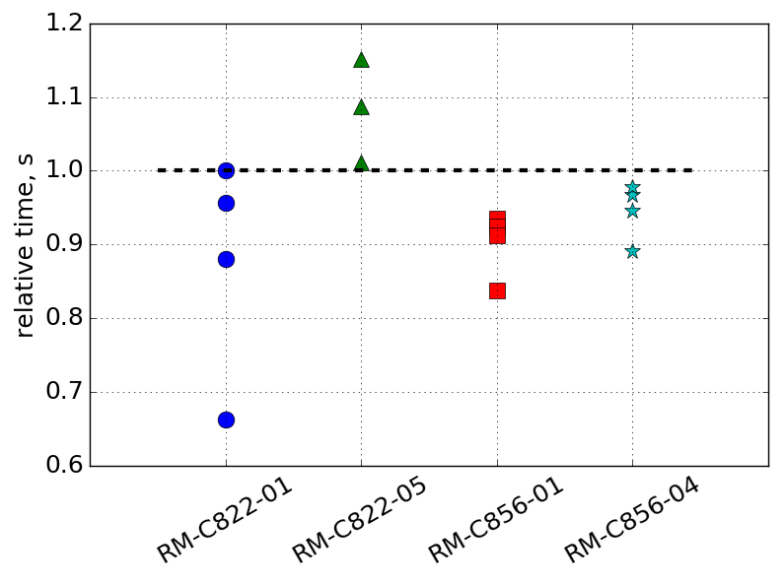

Figure 14. Comparison of relative time for $\tau \mathrm{P} 90$

The same type of comparison is made in Figure 15 and Figure 16, but now for $\tau_{\mathrm{T} 200}$ and $\tau_{\mathrm{T} 500}$, respectively. For

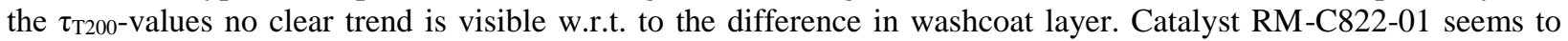
perform a little bit worse, but the other DUS washcoated catalyst shows a similar performance as the AU(B) washcoated catalysts. This supports the hypothesis postulated above that for the initial part of the transient phase the influence of the thermal mass is minimal.

The DUS washcoated catalysts perform better when considering the $\tau_{\mathrm{T} 500}$-values. Comparing Table 1 and Table 2 shows that the relative amount of active phase is less for the DUS washcoated catalyst. From this point of view the results are counterintuitive as one would expect that the more active phase is present the higher the conversion rate would be. However, it should be kept in mind that catalytic decomposition of HTP is mainly taking place at lower temperatures. From about $450{ }^{\circ} \mathrm{C}$ onwards th rate of thermal decomposition is generally higher. That also means that the active phase acts as a heat sink above that temperature. As the active phase content for the DUS tested monoliths is considerably lower in comparison with the other catalysts, it could explain why the $\tau_{\mathrm{T} 500}$-values are lower, but show hardly any difference in the $\tau_{\mathrm{T} 200}$-values. Further testing and analysis is currently performed to confirm or reject this hypothesis.

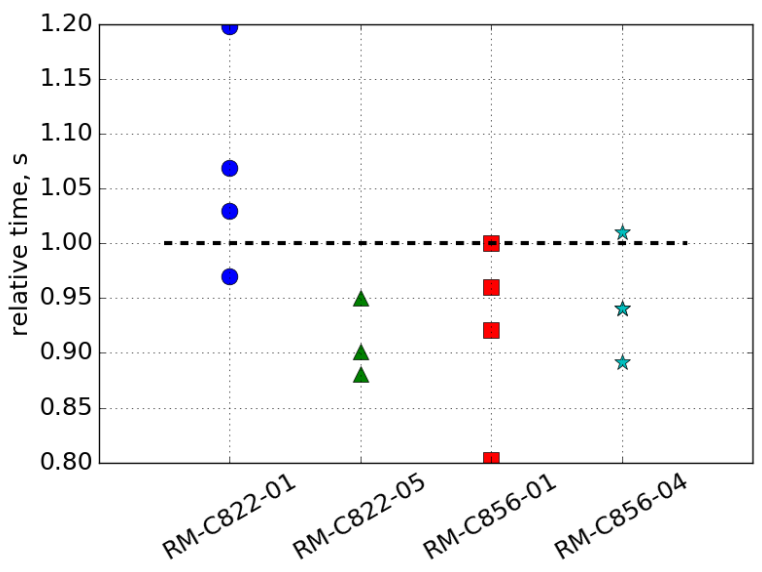

Figure 15. Comparison of relative time for $\tau_{\mathrm{T} 200}$

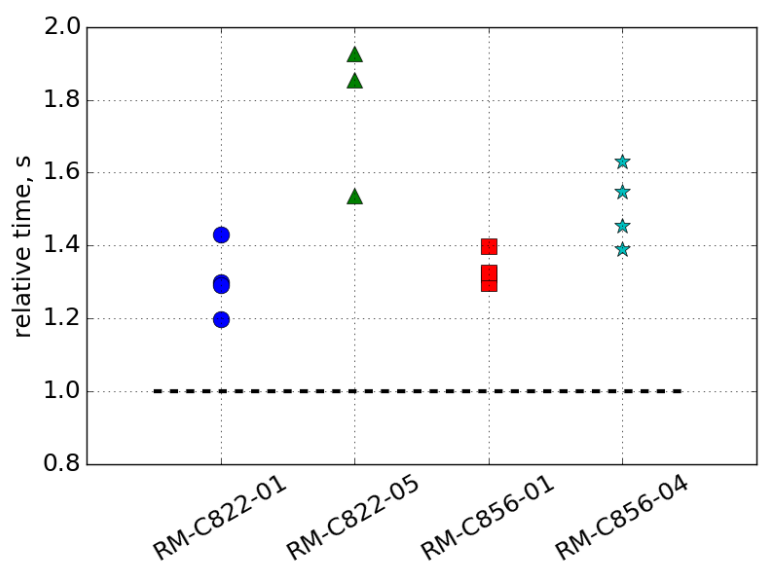

Figure 16. Comparison of relative time for $\tau_{\mathrm{T} 500}$

12

American Institute of Aeronautics and Astronautics 


\section{Conclusion}

With the recently developed technology for printing ceramic structures, new possibilities open up for optimising monolithic catalysts. Complex 3D internal geometries make it possible to increase the effectiveness of the catalyst while keeping the pressure drop within limits.

Decomposition tests revealed that there is no difference in steady state temperature performance when comparing catalysts with a printed support structure with catalysts with an extruded support structure. The transient pressure performance is neither affected by the manufacturing process of the monoliths. An effect is visible though for the transient temperature response. It was determined that an increase in the temperature transient time is proportional to the $A / V$-ratio of the printed catalysts compared to the extruded catalyst. This is noticeable during the second half of the transient phase.

It was also revealed that the porosity of the various catalyst types is different. In general, the porosity is larger for the printed structures. The type of slurry also influences the porosity. A relatively large difference in bulk density was found between slurry C822 and slurry C856 with a density of 2.13 and $1.86 \mathrm{~g} / \mathrm{cm}^{3}$, respectively. The test results show that a less dense structure, i.e. a larger porosity, improves the transient temperature response. It was also found that the $A / V$-ratio is a better indicator for the response time than the $A / \rho$-ratio.

Furthermore, it was shown that during the second half of the transient phase the assumption of a uniform temperature across the wall is not valid. As a consequence, the first half of the transient phase is not affected by thermal mass of the system, but the second half is. This is important to take into account when modelling the thermal response of the catalyst during the transient phase.

Comparison between different types of washcoat layer revealed that the newly developed DUS procedure results in equal or faster transient pressure times and a noticeable faster response during the second half of the transient temperature phase. No such influence was noted in the first half, supporting the hypothesis that the thermal mass of the support structure is of secondary importance during the first part of the transient phase. The faster response in the second half of the transient temperature phase is thought to be the result of a smaller amount of active phase present in the catalyst. It is believed that the active phase acts as a heat sink above a temperature of about $450{ }^{\circ} \mathrm{C}$. Further tests are required to confirm this hypothesis.

It should be noted that the difference in performance between extruded and printed monoliths is caused by a difference in thermal mass and porosity of the support structure. The larger solid volume of the printed monoliths in this study is not a limitation of the manufacturing process, but the result of the current manufacturing process settings. By optimising the printing process thinner structures can be printed. From experience it is known that the wall thickness can be reduced to less than $0.2 \mathrm{~mm}$. In that case the solid volume of the printed monoliths will be very similar to the extruded monoliths.

\section{Acknowledgments}

This project (RHEFORM) has received funding from the European Union's Horizon 2020 research and innovation programme under grant agreement No. 640376.

\section{References}

${ }^{1}$ Musker, A. J., Ryan, J., Wojciech, F., Sobczak, K., Kaniewski, D., Rarata, G., Leininger, S., and Christ, P., "Realistic Testing of PX1 Catalyst Using Near-Anhydrous Hydrogen Peroxide," Rome, Italy: 2016.

2 Negri, M., "Replacement of Hydrazine: Overview and First Results of the H2020 Project Rheform,” Krakow, Poland: 2015.

3 Zube, D., Christofferson, S., Wucherer, E., and Reed, B., "Evaluation of HAN-Based Propellant Blends," Huntsville, Alabama, USA: American Institute of Aeronautics and Astronautics, 2003.

${ }^{4}$ Krejci, D., Woschnak, A., Schiebl, M., Scharlemann, C., Ponweiser, K., Brahmi, R., Batonneau, Y., and Kappenstein, C., "Assessment of Catalysts for Hydrogen-Peroxide-Based Thrusters in a Flow Reactor," Journal of Propulsion and Power, vol. 29, Mar. 2013, pp. 321-330.

5 Palmer, M. J., Musker, A. J., Roberts, G. T., and Ponce-de-Leon, C., "Manufacture , Assessment and Down-Selection of Catalysts for the Decomposition of Hydrogen Peroxide," Proceedings of the 4th European Conference for Aerospace Sciences (EUCASS), St. Petersburg, Russia: 2011.

6 Dolci, S., Dell'Amico, D. B., Pasini, A., Torre, L., Pace, G., and Valentini, D., "Platinum Catalysts Development for 98\% Hydrogen Peroxide Decomposition in Pulsed Monopropellant Thrusters,” Journal of Propulsion and Power, vol. 31, Jul. 2015, pp. 1204-1216.

7 Essa, K., Hassanin, H., Attalah, M., Adkins, N., Musker, A. J., Roberts, G. T., Tenev, N., and Smith, M., "Development and Testing of an Additive Manufactured Catalyst Bed for HTP Thruster Applications," Rome, Italy: 2016.

8 Spores, R. A., "GPIM AF-M315E Propulsion System," Orlando, Florida, USA: American Institute of Aeronautics and Astronautics, 2015. 
9 Whitmore, S. A., Merkley, D. P., Judson, M. I., and Eilers, S. D., "Development and Testing of a Green Monopropellant Ignition System," American Institute of Aeronautics and Astronautics, 2013.

${ }^{10}$ Wucherer, E. J., Cook, T., Stiefel, M., Humphries, R., and Parker, J., "Hydrazine Catalyst Production - Sustaining S-405 Technology," Huntsville, Alabama, USA: American Institute of Aeronautics and Astronautics, 2003.

${ }^{11}$ Price, T. W., and Evans, D. D., The Status of Monopropellant Hydrazine Technology, Pasadena, California, USA: Jet Propulsion Laboratory, 1968.

12 "DLR - Institut für Raumfahrtantriebe - Rheform at a glance" Available: http://www.dlr.de/ra/desktopdefault.aspx/tabid10285/17619_read-42041/.

${ }^{13}$ Schwentenwein, M., and Homa, J., “Additive Manufacturing of Dense Alumina Ceramics," International Journal of Applied Ceramic Technology, vol. 12, Jan. 2015, pp. 1-7.

${ }^{14}$ Koopmans, R.-J., Schuh, S., Bartok, T., Batonneau, Y., Brahmi, R., Kappenstein, C., Scharlemann, C., and Valencia Bel, F., "Experimental Investigation and Analysis of Catalysts for Hydrogen Peroxide Based Thrusters," Rome, Italy: 2016.

${ }^{15}$ Krejci, D., Woschnak, A., Scharlemann, C., and Ponweiser, K., "Structural impact of honeycomb catalysts on hydrogen peroxide decomposition for micro propulsion," Chemical Engineering Research and Design, vol. 90, Dec. 2012, pp. 23022315.

${ }^{16}$ Maleix, C., Chabernaud, P., Brahmi, R., Beauchet, R., Batonneau, Y., Kappenstein, C., Koopmans, R.-J., Schuh, S., Bartok, T., Schwentenwein, M., Spitzbart, M., and Scharlemann, C., "Development of catalytic materials for decomposition of ADN-based monopropellants," Proceedings of the 7th European Conference for Aerospace Sciences (EUCASS), Milan, Italy: 2017. 